\title{
Preface \\ Tricksters at Play
}

\section{Eshu's cap}

This is a book about persuasion, deception and trust and begins with a trickster's journey. We take our lead from Robert Farris Thompson, who eloquently traces the spread of West African culture throughout the diaspora of the New World. He begins by acknowledging the central importance of orisha (gods) in carrying African expressive genius - the 'flash of the spirit' - across the Atlantic. When calling on the orisha for guidance, West Africans begin with Eshu-Elegbara, a powerful Yoruba and Fon deity endowed with àshe, the 'force to make all things happen and multiply' (1983: 18). As with other tricksters, Eshu is sexual, of ambiguous gender and a messenger to the gods about human affairs. Eshu represents chance and uncertainty; where the trickster rules, anything can happen. Eshu creates disorder to test the status quo and keep culture moving along. And Eshu is associated with the crossroads, both as a physical place to offer tribute and symbolically, as a place to speak in riddles and paradoxes, where the mind might go in many different directions searching for answers. At the crossroads, we make decisions about which way to go. We take a risk and learn to trust.

In a West African folktale about Eshu, two men swear vows of eternal friendship without first paying tribute to the god of chance. Eshu decides to test them and fashions a cloth cap with black on one side and white on the other. Wearing this two-coloured cap, Eshu passes along the road between the friends, who are working in neighbouring fields. One of the men insists he sees Eshu wearing a white cap, while the other is certain the god is wearing a black one. The ensuing argument is heated and attracts the attention of their neighbours.

Eshu soon returns, appearing cool and pretending not to know what is happening. When the men explain their disagreement, Eshu declares they are both right: 
As you can see, one side is white and the other is black. You each saw one side and, therefore, are right about what you saw ... When you vowed to be friends always, to be faithful and true to each other, did you reckon with Eshu? Do you know that he who does not put Eshu first in all his doings has himself to blame if things misfire? (Ogundipe, in Gates [1988] 1989: 35)

Cultural critic Louis Henry Gates finds deep insight into the 'indeterminacy of interpretation' (35) in this myth. For Gates, both friends are right, and both are also wrong. The hat is both black and white, but the 'folly depicted here is to insist ... on one determinate meaning, itself determined by vantage point' (35).

The story of Eshu's cap illustrates the paradox that deception can reveal truth - an important insight into persuasion and propaganda. Eshu teaches us that context shapes meaning; point of view determines belief; and truth is contingent. Do we know for certain that we perceive the same events as those around us? Eshu reminds the two friends to make allowances for difference, ambiguity, uncertainty and possibility. Eshu's trick reminds us to question our certainty when interpreting symbolic communication.

Gates takes Eshu's playful deceptions as a model to define the cultural critic's role. The critic 'improvises' on the given materials, repeating and revising previous works, translating meanings, making connections, circulating new texts. Gates calls this work 'signifyin(g)' to suggest its dual association with semiotics (signifying) and African-American word play (signifyin'). The signifyin(g) cultural critic searches for connections to express cultural values and beliefs, always with intent to invigorate, renew and foster understanding. Interpretation is always 'indeterminate' - unfinished and provisional because we have different points of view, and these differences can make communication difficult and messy. In this text, we will perform as signifyin(g) critics by looking at various cultural practices regarding persuasion and influence, trying to remain open to differences of interpretation and opinion. In difference lies truth.

In her exploration of Winnebago Native American culture, anthropologist Barbara Babcock-Abrahams (1975) uses the phrase 'a tolerated margin of mess' to describe the trickster's role in creating productive disorder. Out of the trickster's mess come new perspectives and insights. The Greek god Hermes, North American Coyote, Norse Loki, Yoruba Eshu, Sufi Nasruddin and Hindu Krishna all may be 'foolish' and disruptive, but they bring gifts as well, including the gift of communication and the arts of persuasion and deception. 
Their tricks are teaching stories. Krishna steals butter as a child and then denies it, asking his mother: 'Doesn't everything in the house belong to us?' 'All tricksters do this', comments Lewis Hyde, '[t]hey lie in a way that upsets our very sense of what is true and what is false, and therefore help us reimagine this world'. Aristotle attributes the birth of Western literature to Homer's creative lies: the Greek oral poet 'taught us the art of framing lies the right way ... [c]lever at deceit, tricksters are clever at seeing through deceit, and therefore at revealing things hidden beneath the surface' (Hyde 2011: n.p.). Hyde emphasises the paradox of the trickster's performances: 'the origins, liveliness, and durability of cultures require that there be space for figures whose function is to uncover and disrupt the very things that cultures are based on' (1998: 9). Cultures need creative disruption to evolve and survive, as long as that disruption occurs within a tolerated margin of mess.

Anthropologist Victor Turner identifies tricksters with play, crossing boundaries and renewing culture. Noting the trickster's presence throughout diverse cultures, Turner associates the archetype with the brain's limbic system - a neural crossroads where physical sensations are translated into emotion, decision-making and action on the fly. Turner describes play and ritual as evolving into performance and theatre: 'Like many Trickster figures in myths ... play can deceive, betray, beguile, delude' ([1987] 1988: 169). Play, the essence of improvisation, takes what we have at hand - what is - and recombines it to create something new - what could be. A stick becomes a magic wand. We make paper airplanes. The improvising jazz musician takes a popular melody as the inspiration for creative revisions. For Gates, Turner, Hyde and others, the trickster's creative play is cognitively complex and a gift to culture. We find the trickster's beguiling deceptions in advertising, entertainment, publicity, propaganda and culture jamming - all aiming to influence culture at the crossroads of change.

In what follows, we approach persuasion and propaganda as rhetorical performances involving playful, creative and even devious communication filled with suspect reasoning, colourful language and possible trickery. We will work across disciplines as signifyin $(\mathrm{g})$ cultural critics to reveal the strategies and tactics of the persuasive arts. This theoretical and practical work is filled with paradox and contradiction and requires a doubleness of vision to see both sides of the story, the black and white of Eshu's cap. While advertising, marketing, public relations, political lobbying, rhetoric, persuasion and propaganda are sometimes described as curses of contemporary civilisation, they all depend for their success on creativity, invention, improvisation and 
lively performance - the 'flash of the spirit'. These activities may be disruptive, messy and in bad taste; as with Eshu's tricks, however, they push culture in new directions, both invigorating and destructive.

\section{Exercise questions}

1. In your own words, tell a trickster tale to your study group and discuss what it means.

2. Describe two examples of persuasive performance, one that successfully persuades you and one that does not. What accounts for the difference? Distinguish between the language, the argument and the beliefs or values expressed. Where do your beliefs influence your evaluation?

3. Illustrate how a cultural critic develops new insights by repeating and revising the work of others on one of the themes introduced in the Preface.

4. How do we know what is true or false? 


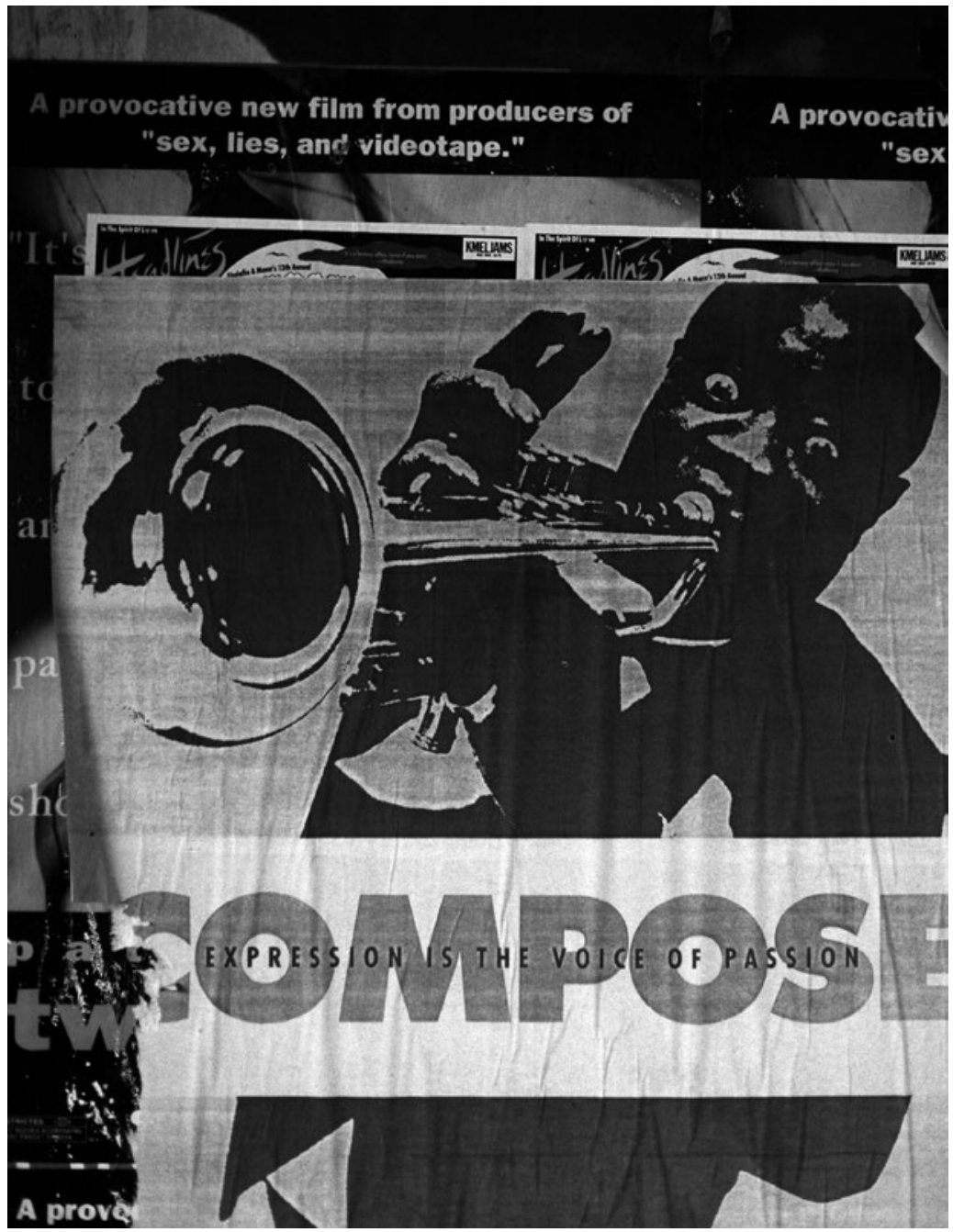

Figure 1 'Compose'. Photo: M. Soules, San Francisco, 1991. Improvisation and performance are important in creative communication. 